\title{
An Analysis of the Research Hotspots and Trends of Enterprise Strategic Management in Domestic
}

\author{
Liu Yimin ${ }^{1, a}$, Chen Jiaying ${ }^{1}$, Xu Xin ${ }^{1}$ \\ ${ }^{1}$ Department of Corporation Administration, Sichuan Agricultural University, Du Jiangyan, Cheng Du, Si Chuan, China \\ a13551294313@163.com
}

\begin{abstract}
Through the visual analysis of the strategic management research literature of CSSCI source journals from 1998 to 2019 in CNKI database, this paper explores the publication volume, the cooperation between authors and research institutions, keyword clustering and keyword emergence of this field, and summarizes the main research hotspots and trends in this field.
\end{abstract}

Keywords: Enterprise strategic management, visual analysis, research hotspots, citespace

\section{国内企业战略管理研究热点与趋势探析}

刘宜敏 ${ }^{1, a}$ ，陈佳芗 ${ }^{1,}$ ，徐金金 1

四川农业大学企业管理，都江堰，成都，四川，中国

a13551294313@163.com

\section{摘要}

本文通过对 CNKI 数据库中 CSSCI 来源期刊 1998-2019 年战略管理研究文献的可视化分析, 对该领域的 发文量、作者和研究机构的合作情况、关键词聚类和关键词突现进行探究, 综合得出该领域研究的主 要热点及趋势。

关键词：企业战略管理；可视化分析；研究热点；Citespace

\section{1. 引言}

企业战略管理作为一门学科起源于 20 世纪 60 年代, 发展至今已有近 60 年的历史。国外不少学者对战略管理 有着深入的研究，例如钱德勒将战略定义为实现目标所 必需的基本行动和资源分配的决策 $[1]$ 。而明茨伯格提出 的战略的 “ $5 \mathrm{p}$ ” 理论认为, 战略是一种计划、计策、模 式、定位、观念 [2]。并且随着战略管理研究成果的丰富 渐渐形成了许多学派, 如产业基础学派、资源基础学派、 制度基础学派等 [3]。而我国企业战略管理兴起于 20 世 纪 90 年代, 经过 20 多年的探索, 尽管与国际前沿热点 问题存在一定的差距, 但我国的战略管理研究通过不断 地摸索确立了研究方向, 完善了研究体系, 渐渐与国际 接轨并向国际有影响力的期刊输送研究成果。因此, 本 文通过 Citespace 可视化分析, 梳理我国企业战略管理 发展脉络, 探究研究热点和演化趋势。

\section{2. 数据来源及研究方法}

\section{1. 数据来源}

中国知网 (CNKI) 作为全球最大的中文数据库, 覆盖学科范围广泛，涵盖资源丰富。为了提高数据的 可靠性和代表性, 本文以 CNKI 数据库作为数据来源。 由于 CSSCI 来源期刊代表着我国最高学术水平和最前 沿的研究成果, 因此在 CNKI 高级检索的 “期刊” 检索 栏目下选择 CSSCI 作为来源期刊, 在 “经济与管理科 学” 分类目录下设定 “主题” 检索条件为 “企业战略 管理”，检索年限为 1998 年至 2019 年，共获得文献 4939 篇, 经过复核确定均为有效文献。将以上文献以 Refworks 格式导出, 并通过 citespace 进行转码, 得 到待分析样本数据。

\section{2. 研究工具与方法}

本研究主要借助美国德雷塞尔大学陈超美教授研 
发的可视化分析软件 Citespace 5.6.R5 对我国企业战略 管理研究相关文献进行分析。该软件是使用 JAVA 程序语 言开发的用于分析某一学科或研究领域在某一时期的研 究热点趋势及前沿动向的科学分析工具, 通过可视化分 析可以直观地呈现多种知识图谱, 包括作者、机构、国 家、关键词、来源以及参考文献和作者共被引等。

本文通过运用 Citespace 对待分析文献信息的处理, 分别得到作者和研究机构的共现知识图谱, 探讨作者、 机构的合作网络; 更改操作选项得到关键词聚类网络图 谱, 研究企业战略管理领域的热点内容; 再进一步得到 关键词突现图，将该领域研究趋势分为 3 个阶段。

\section{3. 企业战略管理研究基本情况的知识图谱分析}

\section{1. 文献发表年代分布及变化}

探析一个领域的研究发展情况可以从该领域的研究 文献数目随年代变化的趋势得出。因此本文为探究我国 企业战略管理研究领域的发展历程, 在 CNKI 中就以上选 中的文献进行计量可视化分析得到图 1 所示的企业战略 管理文献数量时间分布。

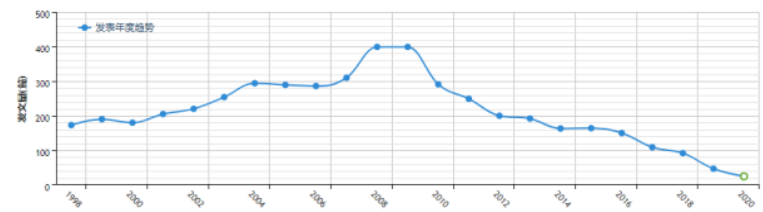

图 1 企业战略管理文献数量时间分布

可以看出尽管自企业战略管理学科起源至今已有 50 余年，但国内对该领域的研究仅有 20 多年。在 1998 年 之前基本呈现高质量研究成果的空白, 我国对企业战略 管理的研究尚浅。从 1998 年到 2007 年处于快速发展阶 段, 国际、国内的学术交流平台不断兴起, 学术思维的 碰撞使得企业战略管理的学者不断涌现并活跃在学术 界。自 2008 年到 2019 年企业战略管理呈缓慢增长态势, 研究体系趋于成熟, 论文成果更具影响力。

\section{2. 作者与研究机构}

在 Citespace 中设置时间跨度为 1998-2019, 时间切 片 1 年, 在 “Node Type” 中选择 author, TOPN=50, 其 它参数设置为默认, 运行 Citespace 得到作者共现知识 图谱（见图 2）。

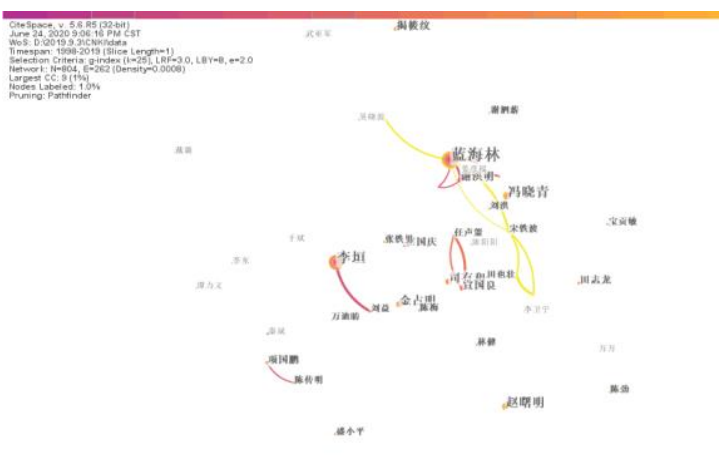

图 2 作者共现知识图谱

由图 2 可知, 节点数最大的学者为蓝海林, 其次 是李垣、冯晓青、赵曙明、金占明、司有和，由此可 见, 这些学者是我国企业战略管理研究领域比较有影 响力的人物。知识图谱密度为 0.0008 , 说明研究者之 间的合作偏少，可以看出知识图谱中的几个合作网络 主要是以该研究领域中影响力较大的研究者为中心形 成的, 如以蓝海林为核心的合作网络, 以李垣为首的 合作网络。几个高产的作者之间没有合作, 且以其为 首的合作网络中的学者与其它团队的学者也没有合 作。除此之外, 该研究领域中更多学者是独立研究, 如冯晓青、金占明、揭䈗纹。由此表明我国企业战略 管理研究中未树立起跨团队的合作意识, 使得该领域 在国内 20 多年的发展历史中形成各团队闭门造车的 局面, 因此企业战略管理研究领域合作网络不够成熟, 学者们的学术交流有待进一步加强。

在 Citespace 中将 “Node Type” 中选择更改为 institution, 其余参数设置不变, 运行 Citespace 得 到研究机构共现知识图谱（见图 3)。

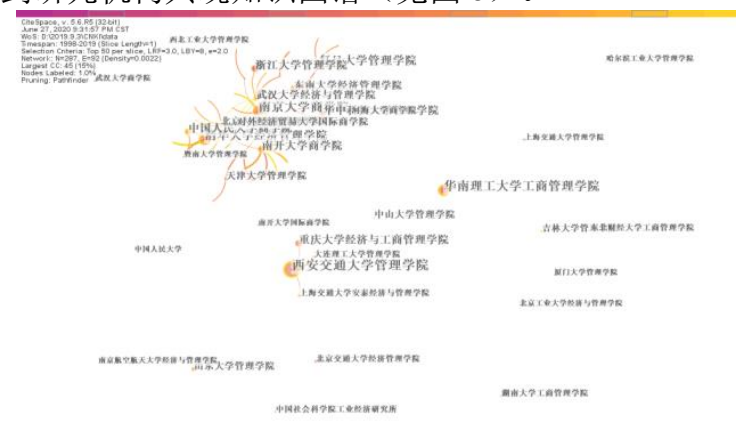

图 3 研究机构共现知识图谱

由图 3 可以看到，几个节点较大的机构有西安交 通大学管理学院、华南理工大学工商管理学院、南京 大学商学院、清华大学经济管理学院, 表明这些机构 发文量较大, 研究成果较丰富。知识图谱密度为 0. 0022, 密度略大于学者之间合作密度, 由图可知机 构之间的密切合作主要集中在以南京大学商学院、清 华大学经济管理学院、复旦大学商学院、南开大学商 学院为代表的一个大型合作网络; 另一合作网络是以 西安交通大学管理学院为核心的小型合作网络。而其 余更多机构缺乏合作意识，且在该领域科研水平最高 
的三所机构没有合作。由此可知各机构并未形成广泛、 紧密的学术交流，机构间的跨区域合作亟待加强。

\section{4. 企业战略管理研究热点及趋势的知识图谱分 析}

\section{1. 企业战略管理研究热点主题}

研究热点主题反映该研究领域的关注点和发展方 向, 而关键词概括了一篇论文的主旨大意, 因此本文将 通过关键词聚类直观地体现企业战略管理领域的热点主 题。

在以上操作基础上更改 Citespace 中 “Node Type” 选项卡下选项为 keyword, 其余参数设置不变, 运行 Citespace 得到关键词共现网络图谱, 再选取 LLR 算法, 得到关键词聚类网络图谱（见图 4)。

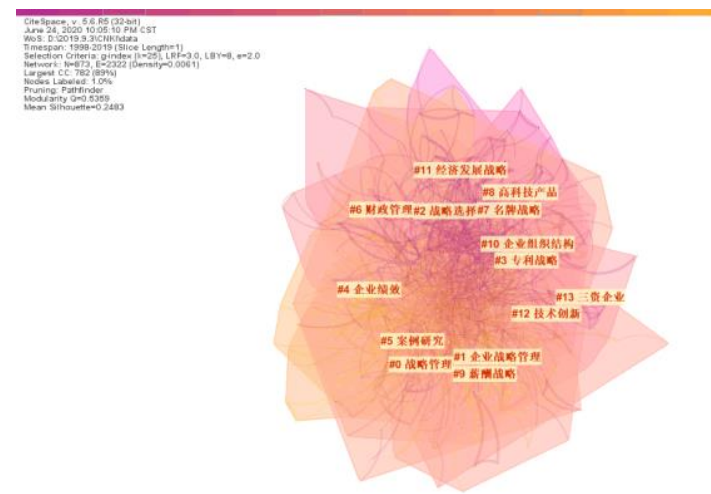

图 4 关键词聚类网络图谱

可视化图谱 Q 值 $=0.5359$, 大于 0.5 , 表明此图谱 呈现合理。由图 4 可知, 通过聚类分析得出了企业战 略管理领域的 14 组聚类, 分别是 $\# 0$ 战略管理、\#1 企 业战略管理、\#2 战略选择、\#3 专利战略、\#4 企业绩 效、\#5 案例研究、\#6 财政管理、\#7 名牌战略、\#8 高 科技产品、\#9 薪酬战略、\#10 企业组织结构、\#11 经 济发展战略、\#12 技术创新、\#13 三资企业。

在 Citespace 中 “Clusters”菜单栏下选择 “Summary Table|Whitelists” 得到关键词共现网络 聚类表, 如表 1 所示。表 1 中 14 组聚类的轮廓值均大 于 0.5 , 说明聚类结果具有可靠性。

表 1 关键词共现网络聚类表

\begin{tabular}{|c|c|c|c|c|}
\hline $\begin{array}{l}\text { 编 } \\
\text { 号 }\end{array}$ & 聚类名 & 轮廓值 & 平均年份 & 聚类标签 \\
\hline$\# 0$ & 战略管理 & 0.803 & 2006 & 战略管理、战略联盟、公司治理、战略转型、技术能力 \\
\hline$\# 1$ & 企业战略管理 & 0.757 & 2003 & 企业战略管理、核心能力、竞争优势、战略管理会计、平衡计分卡 \\
\hline$\# 2$ & 战略选择 & 0.745 & 2006 & 战略选择、区域经济、战略变革、商业模式、中国工业化 \\
\hline$\# 3$ & 专利战略 & 0.8 & 2006 & 专利战略、知识产权、财产权、知识产权战略、智力成果权 \\
\hline$\# 4$ & 企业绩效 & 0.823 & 2008 & $\begin{array}{c}\text { 企业绩效、战略风险、战略人力资源管理、环境不确定性、资产负 } \\
\text { 债率 }\end{array}$ \\
\hline$\# 5$ & 案例研究 & 0.754 & 2008 & 案例研究、国际化战略、专利策略、业务流程再造、整合战略 \\
\hline$\# 6$ & 财政管理 & 0.754 & 2005 & 财政管理、工商局、多角化经营战略、工商行政管理局、模式转型 \\
\hline$\# 7$ & 名牌战略 & 0.78 & 2000 & 名牌战略、海尔集团、思维形式、企业再造、特定资产 \\
\hline$\# 8$ & 高科技产品 & 0.863 & 2000 & 高科技产品、高技术产品、并购市场、战略并购、产业群 \\
\hline$\# 9$ & 薪酬战略 & 0.717 & 2006 & 薪酬战略、企业战略、东道国、人力资源管理系统、动态竞争 \\
\hline$\# 10$ & 企业组织结构 & 0.84 & 1999 & 企业组织结构、经济改革、企业体制、企业结构、经济体制改革 \\
\hline$\# 11$ & 经济发展战略 & 0.882 & 1999 & $\begin{array}{c}\text { 经济发展战略、持续发展战略、可持续发展战略、产业调整、经 } \\
\text { 济结构调整 }\end{array}$ \\
\hline$\# 12$ & 技术创新 & 0.835 & 2006 & $\begin{array}{c}\text { 技术创新、战略薪酬管理、组织结构、现代企业制度、战略变革管 } \\
\text { 理 }\end{array}$ \\
\hline$\# 13$ & 三资企业 & 0.992 & 1998 & 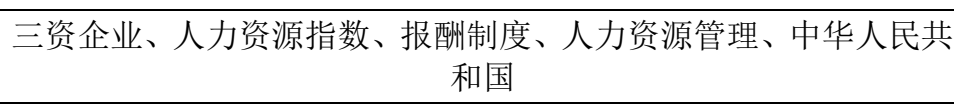 \\
\hline
\end{tabular}


由图 4 和表 1 可知, \#0 战略管理和\#1 企业战略管理 在本文的检索中是同一个概念，从其聚类标签来看，对 企业战略管理方面的研究主要集中在企业的治理和运营 上, 学者们分析了企业的技术能力, 指出企业战略转型 的重要性, 并不断完善企业战略评价体系。逢健等人从 综述战略转型文献入手, 辨明战略转型任务, 并从我国 企业的产业类型、资产规模、资产专用水平 3 个维度对 战略转型难度进行逐一分析和综合分级, 为企业在经营 过程中正确决策提供帮助 [4]。支晓强等人基于定性分 析, 提出了系统性的战略联盟绩效评价, 并将这一维度 容纳至平衡计分卡的框架中，探讨组织间合作与企业内 业绩维度的关系, 实现对平衡计分卡的改进以及企业内、 外部业绩评价的一体化 [5]。同时, 为了适应企业战略管 理对数据整理、预测和分析的新要求, 战略管理会计也 应运而生。\#2 战略选择和\#4 企业绩效正是根据企业战略 管理细化的两个分支, 从聚类标签可以看出, 学者进一 步对不同商业模式和各具特色的经济区的战略选择进行 研究, 如贾立文等人认为尽管伴随着新兴金融业态的发 展，传统商业银行面临严峻挑战，但商业银行的安全、 稳健等特征有利于弥补互联网金融在法律保障及制度建 设方面的不足, 从而融入互联网金融模式, 实现有效互 联网金融体系 [6]; 而胡查平则针对传统制造企业服务化 战略转型提供了理论依据 [7]。同时, 学者们就鲍曼悖论 - - 跨企业绩效与战略风险负相关，对绩效和战略风险 间的相关问题开展了大量研究; 另外基于环境不确定性 的调节作用对企业绩效的探究也不断涌现。\#3 专利战略、 \#7 名牌战略、\#9 薪酬战略是三个战略名词。分别分析三 个聚类的标签, 随着人们对知识产权等权利的重视, 越 来越多企业主动以专利权申请的方式保护自己的竞争优 势, 而学术界也对专利战略相关问题做出研究, 最早的 专利战略 CSSCI 可以追溯到 1998 年, 是郑友德归纳总结 出日本企业的十大专利战略, 并在此基础上探讨了日本 企业是如何利用这些战略来占领国内国际专利市场的 [8]。由于海尔集团以高新技术制造优质电器, 形成名牌 产品群, 享誉国内外, 1999-2004 年, 大量学者以海尔集 团作为案例研究名牌战略, 为企业转型提供新思维。薪 酬战略主要聚焦人力资源管理, 利用生命周期等理论对 薪酬体系的构建进行研究。\#6 财政管理、\#10 企业组织 结构、\#11 经济发展战略、\#13 三资企业这四组聚类均是 与国家层面相连的, 研究者们主要讨论经济体制改革下 企业面临的组织结构调整等挑战, 以及中国三资企业的 人力资源研究, 指出其优势和存在的问题。\#8 高科技产 品, 由于这一类产品的研发管理具有较大的难度, 需要投 入大量人力、物力, 因此需制定有效可行的研发战略, 如高杰等人针对我国高科技产品研发管理中存在的误区， 提出了研发产品技术选择、研发技术管理、研发组织管 理、研发风险管理、研发质量管理、研发人力资源管理 的对策 [9]。\#12 技术创新与多个聚类都有共现联系, 是 由于如今企业面对市场竞争离不开技术创新这一重要战 略工具, 更有学者针对企业技术战略探讨其内涵。

\section{2. 企业战略管理研究趋势分析}

突现词是某个时期突然高频出现的词汇，通过分 析突现词可以得到在我国企业战略管理领域各个时期 的热点主题。在 Citespace 中基于以上操作, 选择控 制面板中的 “Burstness”选项卡，设置 minimum Duration 为 2 , 点击 refresh 后选择 view 得到关键词 突现图（见图 5)。由图可将我国企业战略管理研究 趋势分为 3 个阶段。

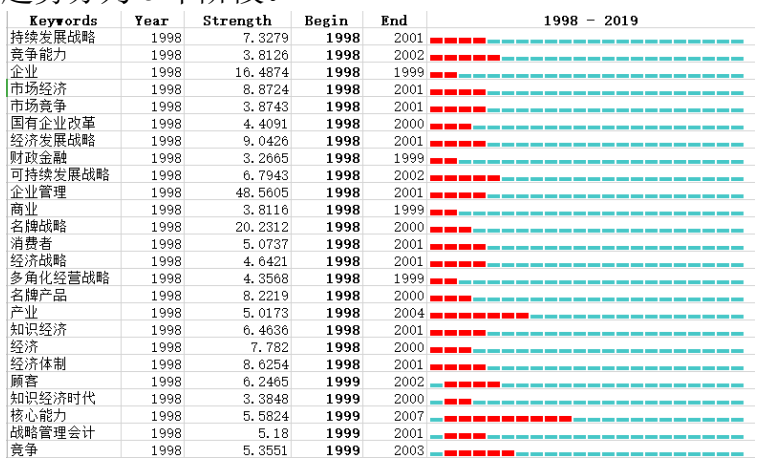

图 5 关键词突现图

第一阶段: 1998-----1999 年。这一时期的突现 词有企业、财政金融、商业、多角化经营战略。研究 定位较清晰, 是战略管理研究的萌芽阶段, 随着我国 学术交流平台的发展, 企业战略管理研究质量显著提 高。在社会主义市场经济体制逐渐完善的背景下，我 国市场逐渐向买方市场转变, 企业间的竞争愈加激烈, 提高企业经营管理水平的需求迫在眉睫，学者通过对 国外战略管理研究成果的述评将这一概念引入，并从 多个角度分析我国企业持续发展的新途径。

第二阶段：2000-2007 年。这一时期的突现词有 持续发展战略、竞争能力、市场经济、市场竞争、国 有企业改革、经济发展战略、可持续发展战略、企业 管理、名牌战略、消费者、经济战略、名牌产品、产 业、知识经济、经济、经济体制、顾客、知识经济时 代、核心能力、战略管理会计、竞争。该阶段是全面 发展期, 我国战略管理研究成果高速增加, 中国企业 面向国际化发展的方向明确，在买方市场的大环境下， 企业对战略管理的重视度提高。学术界对竞争能力的 研究成为一大主流研究方向, 在知识经济的背景下, 人才成为企业的重要资源, 提出知识管理战略概念。

第三阶段：2008 至今。这一时期是我国企业战略 管理的成熟期, 国内学者的关注点与国际接轨, 并通 过对国际研究成果的本土化完善和创新, 运用到我国 的实际问题中。

\section{5. 结语}

本文首先通过 CNKI 数据库对待分析样本的计量 可视化分析得出战略管理研究发文量的 3 个阶段, 分 别是研究空白期、快速增长期和成熟前期。之后利用 Citespace 可视化分析软件通过对待分析文献信息的 
处理, 分别得到作者和研究机构的共现知识图谱, 通过 分析发现我国企业战略管理研究中未树立起跨团队的合 作意识, 企业战略管理研究领域合作网络不够成熟, 学 者们的学术交流有待进一步加强; 同样的, 各机构缺乏 广泛、紧密的学术交流, 机构间的跨区域合作亟待加强。 从关键词共现来看, 该领域的研究热点主要集中在对不 同商业模式和各具特色的经济区的战略选择研究; 战略 与绩效问题的思考, 对企业战略评价体系的完善; 就经 济体制改革下企业面临的组织结构调整的分析等。最后 通过对突现词的讨论, 将我国企业战略管理研究趋势分 为 3 个阶段, 分别是萌芽阶段、全面发展阶段和成熟阶 段, 通过分析, 重现了我国学术研究从汲取国外研究成 果, 丰富自身理论储备到建立我国战略管理研究体系、 确立研究方向再到研究创新的过程。

\section{REFERENCES}

[1] Chandler, A. (1962) Strategy and structure: chapters in the history of the industrial enterprise. J. Technology and Culture., 5(1).

[2] Mintzberg, H., Lampel, J., Quinn, J.B. (2014) Strategic Management: Concepts and Cases (10th edition). Renmin University press, Beijing. 2014.

[3] Peng, M.W., Sun, S.L., Pinkham, B. (2009) The Institution-Based View as a Third Leg for a Strategy Tripod. J. Academy of Management Perspectives., 23(3): 63-81.

[4] Pang, J., Zhu, X.M. (2014) Strategic transformation of Chinese enterprises: task definition and difficulty classification. J. Science and technology progress and countermeasures., 31(12): 75-79.

[5] Zhi, X.Q., Dai, L. (2012) Theoretical Development of Inter-organizational Performance Evaluation and Improvement of balanced Scorecard: Based on strategic Alliance Scenario. J. Accounting Research., (04): 79-86+95.

[6] Jia, L.W., Zheng, Y., Zhang, J. (2015) Strategic choice of commercial Banks under the new financial model. J. Management modernization., 35(02): 37-39.

[7] $\mathrm{Hu}$ C.P. (2016) Service-oriented strategic transformation of manufacturing industry: a conceptual implementation framework based on case studies of three local manufacturing enterprises. J. China circulation economy., 30(08): 47-55.

[8] Zheng, Y.D. (1998) Preliminary Study on Patent Strategy of Japanese enterprises. J. Scientific Research Management., (01): 36-40+35.
[9] Gao, J., Liu, L., Cai, H. (2003) Strategy of research management of high-tech Products. J. Scientific Management Research., (02): 74-78. 